\title{
Influence of Segregation on Pavement Performance of Asphalt Mixture
}

\author{
Zhi-quan Wei, a, Qi-fa Lu ${ }^{1, b}$ and Jun $\mathrm{Yu}^{1, \mathrm{c}}$ \\ ${ }^{1}$ Dong xiang branch, Highway bureau of Fuzhou City, Fuzhou 344001, China \\ ${ }^{2}$ Jiangxi transportation consultation company, Nanchang 330000, China \\ ${ }^{3}$ Jiangxi province traffic construction engineering quality supervision administration, Nanchang \\ 330000, China \\ a312765188@qq.com, b986309697@qq.com, ‘448724693@qq.com
}

Keywords. road engineering, asphalt mixture, grading segregation, pavement performance

\begin{abstract}
In order to solve the research deficiencies of influence of segregation on the performance of asphalt pavement, the segregation simulation and performance test were conducted. In terms of different grading deviation, the classification standard of segregation was divided into four levels. Subsequently, asphalt mixtures corresponding with different segregation levels were used to conduct pavement performance tests. The results indicated that the reduction of the fine aggregate segregation will improve the Marshall residual stability of immersion. With the increasing of segregation, the moisture stability performance of asphalt mixture was not significantly decreased. Whether it was the increasing of segregation of fine aggregate or coarse aggregate, the high temperature stability of asphalt mixture was decreased.
\end{abstract}

\section{Introduction}

Segregation is defined that the production gradation of hot asphalt mixtures mixed evenly in a mixing plant are not in conformity with the design gradation, in other words, the inhomogeneity changes of physical and mechanical properties appear in the asphalt mixtures. Aggregate segregation, compaction degree and temperature segregation are three kinds of phenomenon existing in the construction process of asphalt pavement [1 2]. According to the aggregate segregation, it is considered that the void in the area where coarse aggregates concentrate will grow, with the appearance of moisture damage. Meanwhile, the resistance to crack and tensile strength of mixtures in this area are weak, leading to the serious reduction of fatigue life. On the contrary, the void and asphalt-aggregate ratio in the area where fine aggregates concentrate will decrease and increase, respectively, leading to the pavement damage such as permanent deformation, flushing and push-up [3 5].

At present, the researches on the segregation of asphalt mixture mainly focus on evaluation index and measurement method. The researches for segregation mechanism, effect of segregation on pavement performance of mixtures and forming process of segregation in construction are very limited. Therefore, the aims of this paper are to study the pavement and physical performance of asphalt mixture after occurring segregation so as to improve the construction quality of pavement.

\section{Segregation Simulation of Asphalt Mixture}

\subsection{Standard Grading}

Before the simulation of segregation, a standard grading should be chosen to closely combine with the actual construction, shown as in Fig 1. 


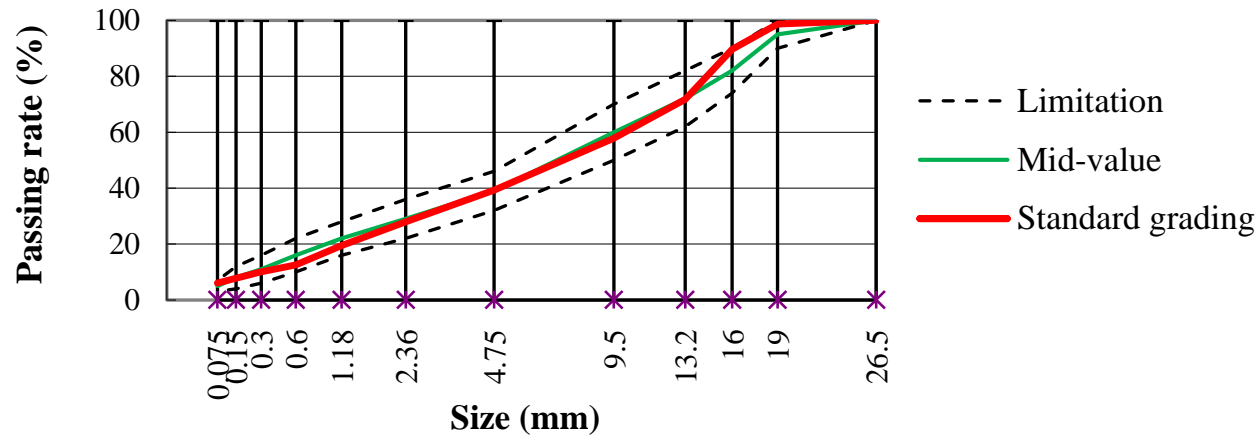

Fig 1 Grading curve

\subsection{Design of Gradation Segregation}

In this paper, the classification standard of segregation was obtained by referring to the design of critical segregation grading [6], shown as in Tab 1.

Tab 1 Classification standard of segregation

\begin{tabular}{|c|c|c|c|c|}
\hline Type & $\begin{array}{c}\text { No } \\
\text { segregation }\end{array}$ & $\begin{array}{c}\text { Mild } \\
\text { segregation }\end{array}$ & $\begin{array}{c}\text { Moderate } \\
\text { segregation }\end{array}$ & $\begin{array}{c}\text { Severe } \\
\text { segregation }\end{array}$ \\
\hline Grading deviation & $<10 \%$ & $10 \% \sim 20 \%$ & $20 \sim 35 \%$ & $35 \%$ \\
\hline
\end{tabular}

It can be seen from Tab 1, the boundary value of mild segregation, moderate segregation and severe segregation are $10 \%, 20 \%, 35 \%$, respectively. In terms of this classification, the design of segregation grading must make sure the grading deviation between each gradation and standard gradation are three kinds of boundary value. Subsequently, the segregation grading curves were obtained and shown as in Fig 2 and the asphalt-aggregate ratio was shown as in Tab 2.

Tab 2 Asphalt-aggregate ratios after segregation

\begin{tabular}{|c|c|c|}
\hline \multirow{2}{*}{ Segregation type } & Asphalt-aggregate ratio \\
\hline \multirow{2}{*}{ Mild segregation } & $1 \#$ & 3.7 \\
\cline { 2 - 3 } & $2 \#$ & 4.7 \\
\hline \multirow{2}{*}{ Moderate segregation } & $3 \#$ & 3.2 \\
\cline { 2 - 3 } & $4 \#$ & 5.3 \\
\hline \multirow{2}{*}{ Severe segregation } & $5 \#$ & 2.5 \\
\cline { 2 - 3 } & $6 \#$ & 6.0 \\
\hline
\end{tabular}

The aggregates used in the following test were a kind of limestone and the binder was SBS modified asphalt. The specifications of materials were satisfied the technical specification for construction of Highway asphalt pavement [7].

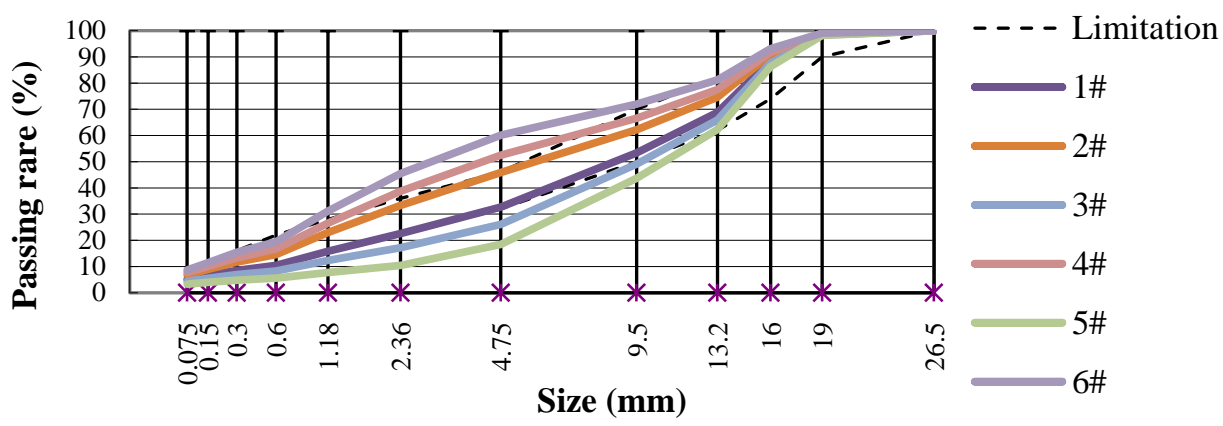

Fig 2 Segregation grading curve

\section{Pavement Performance Tests of Asphalt Mixture}

\subsection{Test of Immersion Marshall}

The test of immersion Marshall is a method to evaluate the moisture stability of asphalt mixture, which is more emphasis on the resistance to moisture damage. The following formula is used to 
calculate the Marshall stability of immersion [8]:

$$
M S_{0}=\frac{M S_{1}}{M S} \times 100
$$

Where, $\mathrm{MS}_{0}=$ Marshall residual stability of immersion, \%; $\mathrm{MS}_{1}=$ Marshall stability of immersion for 48h, kN; MS= Marshall Stability, kN.

\subsection{Freeze-thaw Splitting Test}

The freeze-thaw split cycle is a means to evaluate the moisture stability of asphalt mixture, which is different from the Marshall stability of immersion, and the immersion environment of the freeze-thaw splitting cycle is more rigorous and more close to the actual situation[9]. The splitting tensile strength ratio is calculated by the following formula [8]:

$$
T S R=\frac{R_{T 2}}{R_{T 1}} \times 100
$$

Where, TSR $=$ splitting tensile strength ratio, $\% ; \mathrm{R}_{\mathrm{T} 2}=$ splitting tensile strength after freezing and thawing cycles, $\mathrm{MPa} ; \mathrm{R}_{\mathrm{T} 1}=$ splitting tensile strength without freezing and thawing cycles, MPa.

\subsection{Rutting Test}

Rutting test is used to evaluate the high temperature stability of asphalt mixture [10]. The test temperature is $60^{\circ} \mathrm{C}$ and the wheel pressure is $0.7 \mathrm{MPa}$. The Size of a sample is $300 \mathrm{~mm} \times 300 \mathrm{~mm} \times 50 \mathrm{~mm}$, and the dynamic stability is calculated as follows [8]:

$$
D S=\frac{\left(t_{2}-t_{1}\right) \times N}{d_{2}-d_{1}} \times C_{1} \times C_{2}
$$

Where, DS $=$ dynamic stability of asphalt mixture, $/ \mathrm{mm}$; $\mathrm{d}_{1}=$ deformation at the $45 \mathrm{~min}$, $\mathrm{mm}$; $\mathrm{d}_{2}=$ deformation at the $60 \mathrm{~min}, \mathrm{~mm} ; \mathrm{t}_{2}-\mathrm{t}_{1}=15 \mathrm{~min} ; \mathrm{N}=$ Wheel rolling speed, generally is $42 \mathrm{times} / \mathrm{min}$; $\mathrm{C}_{1}=1.0 ; \mathrm{C}_{2}=1.0$.

\section{Test Results and Analysis}

\subsection{Moisture Stability}

The test result of immersion Marshall was shown in Tab 3. It can be seen that there is no linear relationship between the asphalt aggregate ratio of asphalt mixture and the Marshall residual stability. The reduction of the fine aggregate segregation will improve the Marshall residual stability of immersion. Meanwhile, in the moderate segregation, the stability of immersion for $48 \mathrm{~h}$ is slightly greater than the stability of immersion for $0.5 \mathrm{~h}$. In addition, the coarse aggregate segregation makes Marshall residual stability of immersion increased firstly and then decreased. However, no matter what kinds of segregation, Marshall residual stability can meet the requirements of more than 85\%, as well as the requirement of more than $91.6 \%$ under the standard proportion. Thus, segregation can improve the moisture stability of asphalt pavement.

Tab 3 Immersion Marshall stability of segregation grading

\begin{tabular}{c|c|c|c|c}
\hline Grading number & $1 \#$ & $2 \#$ & $3 \#$ & $4 \#$ \\
\hline Marshall stability of immersion for 48h $(\mathrm{kN})$ & 9.64 & 16.56 & 9.14 & 15.12 \\
\hline Marshall stability(kN) & 9.76 & 13.31 & 6.92 & 15.27 \\
\hline Marshall residual stability of immersion (\%) & 98.8 & 124.4 & 132.1 & 99.0 \\
\hline
\end{tabular}

Besides, the result of freeze-thaw splitting test for evaluating the moisture stability was shown in Tab 4. It can be seen that the reduction of fine aggregate will contribute to the improvement of freeze-thaw splitting strength ratio. In terms of using the moisture stability of asphalt mixture with segregating to evaluate segregation types, the difference between $7 \%$ segregation and $13 \%$ segregation is not obvious. Meanwhile, with the increasing of segregation, the moisture stability performance of asphalt mixture was not significantly decreased. 
Tab 4 Splitting tensile strength ratio of segregation grading

\begin{tabular}{c|c|c|c|c}
\hline Grading number & $1 \#$ & $2 \#$ & $3 \#$ & $4 \#$ \\
\hline $\begin{array}{c}\text { splitting tensile strength after } \\
\text { freezing and thawing cycles (MPa) }\end{array}$ & 0.682 & 0.833 & 0.825 & 0.517 \\
\hline $\begin{array}{c}\text { splitting tensile strength without } \\
\text { freezing and thawing cycles (MPa) }\end{array}$ & 0.768 & 0.985 & 0.922 & 0.596 \\
\hline splitting tensile strength ratio (\%) & 88.9 & 84.6 & 89.4 & 86.8 \\
\hline
\end{tabular}

\subsection{High temperature stability}

Tab 5 showed the dynamic stability of asphalt mixture under different segregation grading. Compared to 15000 times/mm dynamic stability of standard mixture, whether it was the increasing of segregation of fine aggregate or coarse aggregate, the dynamic stability was decreased (i.e. the high temperature stability of asphalt mixture was decreased). But compared to coarse aggregate, the increase of fine aggregate was obviously greater impact on the dynamic stability of asphalt mixture.

Tab 5 Dynamic stability of segregation grading

\begin{tabular}{ccccc}
\hline Grading number & $1 \#$ & $2 \#$ & $3 \#$ & $4 \#$ \\
\hline deformation at the $45 \mathrm{~min}, \mathrm{~mm}$ & 1.082 & 1.606 & 1.374 & 2.470 \\
\hline deformation at the $60 \mathrm{~min}, \mathrm{~mm}$ & 1.140 & 1.730 & 1.458 & 2.627 \\
\hline dynamic stability, $/ \mathrm{mm}$ & 10862 & 5080 & 7500 & 4012 \\
\hline
\end{tabular}

Subsequently, the surface of rutting sample was analyzed intuitively, shown as in Fig 3 . When fine aggregate segregation increased, the wheel track was very obvious.

Compared with the $7 \%$ segregation, the rutting track of asphalt mixture with $13 \%$ segregation was obvious as well as the deformation.

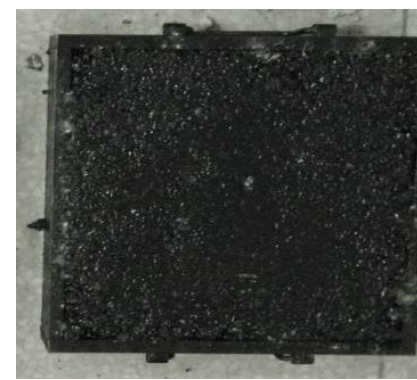

(a) $7 \%$ segregation

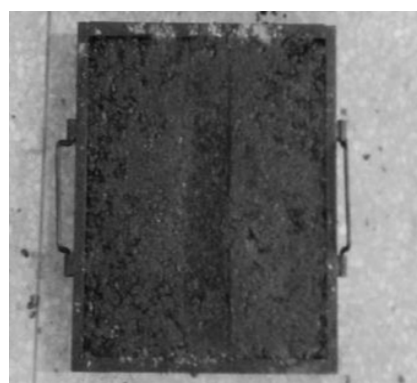

(b) $13 \%$ segregation

Fig 3 Rutting sample with the increase of fine aggregates

\section{Conclusion}

The performance difference of asphalt mixture with different segregation levels can be obtained by conducting correlative tests. With the increasing of segregation level of coarse aggregate, the Marshall residual stability of immersion will increase firstly and then decrease. In terms of using the moisture stability of asphalt mixture with segregating to evaluate segregation types, the difference between $7 \%$ segregation and $13 \%$ segregation is not obvious. Compared to coarse aggregate, the increase of fine aggregate was obviously greater impact on the high temperature stability of asphalt mixture.

\section{Acknowledgments}

The authors acknowledge the financial support of the Jiangxi Provincial Science and Technology Support Program (Project No. 2010T0051), which is sponsored by the Transportation Department of Jiangxi Province, China.

\section{References}

[1] C. Chen, R. C. Williams, T. Ahmed, et al. Quality Control/Quality Assurance Testing for Longitudinal Joint Density and Segregation of Asphalt Mixtures[J]. Construction \& Building 
Materials, 2013, 47(5):80-85.

[2] X. Zheng, J. Xu, L. Cong, et al. Influence of Segregation on Asphalt Mixture Performance[J]. Journal of Highway and Transportation Research and Development, 2008, 11(25):16-20.

[3] S. Chun, H. S. Lee, J. Greene, et al. Effect of Segregation on Coarse Aggregate Structure and Rutting Potential of Asphalt Mixtures[C]// Transportation Research Board 93rd Annual Meeting. 2014.

[4] J. Shen. On Issues of Homogeneity and Separation of Bitumen Mixtures[J]. Journal of Highway and Transportation Research and Development, 2001, 18(6):20-24.

[5] J. Y. Li. The Study Summery of Segregation Characters for Asphalt Mixture Based on Discrete Element Method[J]. Advanced Materials Research, 2014, 1065-1069:818-821.

[6] M. Stroupgardiner, E. R. Brown. Segregation in Hot-mix Asphalt Pavements[J]. Caring National Association for Home Care Magazine, 2000, 14(10):62-5.

[7] Research Institute of Highway. Technical Specifications for Construction of Highway Asphalt Pavements: JTG F40-2004[M]. Ministry of Transport, Beijing, China, 2011.

[8] Research Institute of Highway. Standard Test Methods of Bitumen and Bituminous Mixtures for Highway Engineering: JTG E20-2011[M]. Ministry of Transport, Beijing, China, 2011.

[9] L. B. Gao, X. H. Fan, M. Gao, et al. Experimental Study of Performance of Asphalt Mixture under Freeze-Thaw Circle Test[J]. Advanced Materials Research, 2013, 723:353-360.

[10] Y. Wang, W. Li. Study on High Temperature Performance of Asphalt Mixture Based on Rutting Test[J]. Applied Mechanics \& Materials, 2015, 744-746:1316-1319. 